\title{
Bone marrow fibrosis at diagnosis is associated with TP53 overexpression and adverse prognosis in low-risk myelodysplastic syndrome
}

Myelodysplastic syndrome (MDS) is a heterogeneous group of stem cell clonal alterations, culminating in a high risk of progression to acute myeloid leukaemia (AML) (Greenberg et al, 2012). The prognosis of these patients is commonly determined by the International Prognostic Score System (IPSS), which considers the number of cytopenias, cytogenetic alterations and number of blasts in the bone marrow at diagnosis.

Patients with a lower risk of progression to AML are classified as low risk; however, a subgroup of these patients develops a disease with an aggressive course and a lower survival rate (Mittelman et al, 2010). This clinical heterogeneity reinforces the need to identify auxiliary markers for prognostic stratification systems.

Bone marrow fibrosis is a histological finding in approximately $10-20 \%$ of patients with de novo MDS; however, MDS with fibrosis is not yet recognized as a distinct entity and its prognostic role is still under debate (Ramos et al, 2016).

The immunohistochemical expression of TP53 has been used as a predictive marker for mutations in the TP53 gene in several haematological diseases due to the low-cost and easy to perform technique (Kulasekararaj et al, 2013). Moreover, studies have demonstrated that TP53 expression is an independent adverse prognostic factor in patients with highrisk MDS, being associated with complex karyotype and therapy-related MDS (Kulasekararaj et al, 2013).

Therefore, the present study investigated the impact of bone marrow fibrosis and TP53 expression at diagnosis on the clinical characteristics and overall survival of patients with low-risk MDS.

Seventy-three low-risk MDS patients treated at a reference University Hospital in the northeast of Brazil participated in the study. Patients were stratified according to the IPSS and revised IPSS (IPSS-R) criteria (Greenberg et al, 2012).

Clinical data at diagnosis, such as karyotype, complete blood count, number of blasts, presence of fibrosis and evolution to death or AML, were collected from medical records. TP53 expression was determined by immunohistochemistry, according to Shah et al (2012). Briefly, 5- $\mu \mathrm{m}$ sections of bone marrow were incubated with the p53-DO7 monoclonal antibody (Dako, Santa Clara, CA, USA). TP53 protein was identified by the $\mathrm{ABC}$ - peroxidase technique, staining with
3,3'-Diaminobenzidine (DAB; Dako), and counterstaining with haematoxylin. The percentage and intensity of TP53 staining was assessed based on a total manual count of 1000 granulocytic precursors. TP53 expression was defined as positive for a strong nuclear staining pattern, according to the Modified Quick Score (Kulasekararaj et al, 2013) in at least $1 \%$ of the cells analysed (Saft et al, 2014).

Patients were stratified for the presence of bone marrow fibrosis at diagnosis according to the criteria used by the European Myelofibrosis Network (Thiele et al, 2005). The study was approved by the Research Ethics Committee of the Federal University of Ceará (protocol \#129/12) and all patients agreed to participate. Statistical analysis was performed using the GraphPad Prism 5.0 software (GraphPad Software Inc., La Jolla, CA, USA), using chi-square and Student's $t$ or Mann-Whitney test, according data normality, verified by Kolmogorov-Smirnov test. The Kaplan-Meier curve was performed to verify differences in overall survival. Significance was set at $P<0 \cdot 05$.

The median age of the study patients was 65 years, with a predominance of females (64.3\% females and $35 \cdot 7 \%$ males). Most of the patients $(49 \cdot 32 \%)$ were classified as single-lineage dysplasia, followed by multi-lineage dysplasia (41.09\%), MDS with ringed sideroblasts (6.85\%) and MDS with isolated $\operatorname{del}(5 \mathrm{q})(2 \cdot 74 \%)$.

Patients with bone marrow fibrosis (MF-2 and MF-3) had significantly lower haemoglobin and haematocrit values at diagnosis when compared to patients without fibrosis (MF-0 and MF-1) $(P=0.001)$. High TP53 expression was associated with the presence of bone marrow fibrosis $(P=0.008)$. There was no difference between the other analysed parameters (Table I).

Patients with bone marrow fibrosis $[P=0.0007$, hazard ratio $(\mathrm{HR})=0.02,95 \%$ confidence interval $(\mathrm{CI})=0.002-$ $0 \cdot 20]$ and high TP53 expression $(P=0.0039, \mathrm{HR}=14 \cdot 34$, $95 \% \mathrm{CI}=2 \cdot 0-102 \cdot 8)$ had lower overall survival when compared to patients without these findings. Overall survival in patients with bone marrow fibrosis (MF-2 and MF-3) did not demonstrate a significant difference regarding TP53 expression $(P=0.3794, \quad \mathrm{HR}=2 \cdot 62,95 \% \quad \mathrm{CI}=0 \cdot 34-17 \cdot 40)$ (Fig 1).

Some studies have reported on the importance of bone marrow fibrosis in prognostic characteristics and survival of patients with de novo MDS; however, the role of these 


\begin{tabular}{|c|c|c|c|}
\hline \multirow[b]{2}{*}{ Parameters } & \multicolumn{2}{|c|}{ Low-risk MDS patients } & \multirow[b]{2}{*}{$P$ value } \\
\hline & $\begin{array}{l}\text { MF- } 0 \text { and MF- } 1 \\
(n=57)\end{array}$ & $\begin{array}{l}\text { MF-2 and MF-3 } \\
(n=16)\end{array}$ & \\
\hline $\begin{array}{l}\text { Median of age at diagnosis, } \\
\text { years (range } \pm \text { error) }\end{array}$ & $64 \cdot 14 \pm 2 \cdot 07$ & $65 \cdot 15 \pm 4 \cdot 61$ & 0.777 \\
\hline \multicolumn{4}{|l|}{ Gender } \\
\hline Male & $19(33 \cdot 3 \%)$ & $8(50 \cdot 0 \%)$ & \multirow[t]{2}{*}{$0 \cdot 222$} \\
\hline Female & $38(66 \cdot 7 \%)$ & $8(50 \cdot 0 \%)$ & \\
\hline \multicolumn{4}{|l|}{ Cytogenetics, $n(\%)$} \\
\hline Normal karyotype & $50(87 \cdot 7 \%)$ & $14(87 \cdot 5 \%)$ & \multirow[t]{2}{*}{1.000} \\
\hline Chromosomal aberrations & $7(12 \cdot 3 \%)$ & $2(12 \cdot 5 \%)$ & \\
\hline \multicolumn{4}{|l|}{ Complete blood count } \\
\hline Haemoglobin $(\mathrm{g} / \mathrm{l})$ & $11.57 \pm 0.39$ & $9.039 \pm 0.57$ & 0.001 \\
\hline Haematocrit (\%) & $34.45 \pm 1.05$ & $27 \cdot 17 \pm 1 \cdot 82$ & 0.001 \\
\hline $\mathrm{MCV}(\mathrm{fl})$ & $90.89 \pm 1.42$ & $88 \cdot 82 \pm 3 \cdot 17$ & $0 \cdot 502$ \\
\hline Leucocyte count $\left(\times 10^{9} / 1\right)$ & $4655 \pm 402 \cdot 2$ & $3376 \pm 507 \cdot 7$ & $0 \cdot 110$ \\
\hline Platelet count $\left(\times 10^{9} / \mathrm{l}\right)$ & $161.783 \pm 13.338$ & $198 \cdot 912 \pm 65 \cdot 347$ & $0 \cdot 388$ \\
\hline Bone marrow blasts, $\%$ & $3.069 \pm 0.89$ & $3.678 \pm 1.89$ & 0.778 \\
\hline \multicolumn{4}{|l|}{ TP53 expression } \\
\hline Positive & $11(19 \cdot 3 \%)$ & $9(56 \cdot 25 \%)$ & \multirow[t]{2}{*}{0.008} \\
\hline Negative & $46(80 \cdot 7 \%)$ & $7(43 \cdot 75 \%)$ & \\
\hline
\end{tabular}

Table I. Laboratory parameters at diagnosis in patients with low-risk MDS $(n=73)$.

MCV, mean cell volume; MDS, myelodysplastic syndrome; MF, bone marrow fibrosis.

Bold values indicate $\mathrm{p}<0.05$.
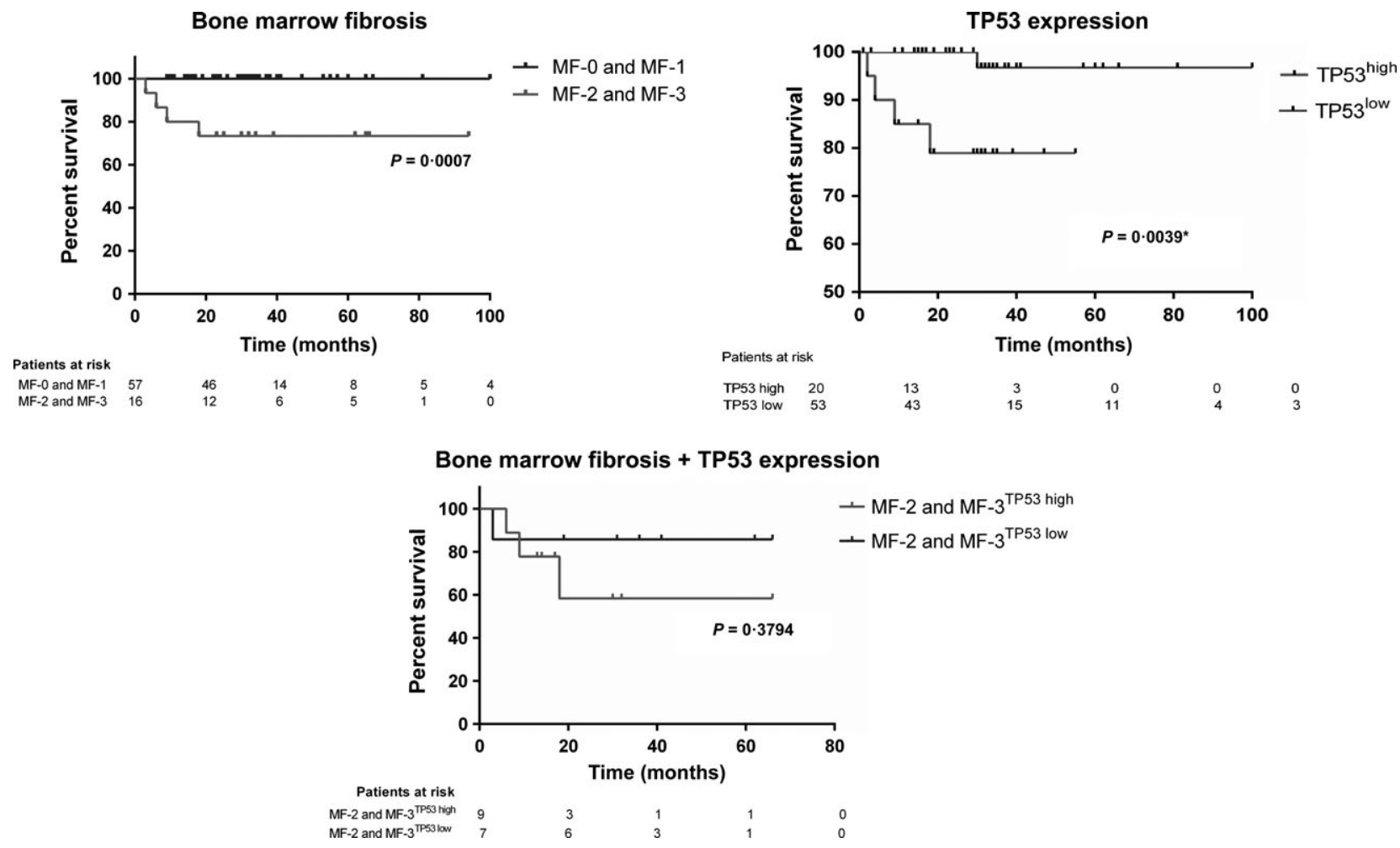

Fig 1. Overall survival of low-risk myelodysplastic syndromepatients regarding bone marrow fibrosis (MF) and high TP53 expression.

markers in patients stratified as low risk has yet to be confirmed. The presence of bone marrow fibrosis has been strongly associated with multi-lineage dysplasia, severe cytopenias, high transfusion dependence and lower overall survival, which can be attributed to bone marrow failure or evolution to AML (Della Porta \& Malcovati, 2011).

The present study showed that in low-risk patients, bone marrow fibrosis was associated with lower haemoglobin 
and haematocrit values, suggesting a higher need for transfusion in this group, as described for patients with MDS, irrespective of risk stratification (Della Porta \& Malcovati, 2011).

The association between the presence of bone marrow fibrosis and high TP53 expression supports the hypothesis that patients with medullary fibrosis at diagnosis may develop an unfavourable clinical course, as high TP53 expression has been frequently reported as an independent prognostic marker in this population (Bejar et al, 2011; Kulasekararaj et al, 2013).

These results corroborate the findings of Loghavi et al (2015), who reported a $61 \cdot 2 \%$ rate of high TP53 expression in patients with MDS and fibrosis. Similarly, Ramos et al (2016) showed an association between bone marrow fibrosis and TP53 protein accumulation. It is possible that there is a biological interaction between mutations in the TP53 gene and bone marrow fibrosis; however, these mechanisms have yet to be elucidated.

Patients with bone marrow fibrosis and high TP53 expression had lower overall survival, indicating that, for low-risk patients, these markers may constitute independent prognostic factors that are capable of differentiating subgroups with different evolution potential within the same risk stratification. Interestingly, in the group with bone marrow fibrosis, TP53 expression did not have a cumulative effect on overall and AML-free survival. This finding may have been influenced by the small number and short follow-up of patients with bone marrow fibrosis.

The results obtained in the present study indicate the importance of using bone marrow fibrosis and TP53 expression analysis in patients with low-risk MDS as auxiliary markers, aiming at attaining a higher predictive power and appropriate therapeutic management.

\section{Author contributions}

FBD and JPV designed the research study; FBD and RPGL performed the research; IZ, FDR and DFC contributed essential reagents or tools; $\mathrm{MCB}$ and TEJS analysed the data; MCB, TEJS, FBD and RPGL wrote the paper; PRLV critically revised the manuscript.

\author{
Fernando B. Duarte ${ }^{1}$ \\ Maritza C. Barbosa ${ }^{2}$ (D) \\ Talyta E. Jesus dos Santos ${ }^{2}$ \\ Romélia P. G. Lemes ${ }^{2}$ iD \\ João P. Vasconcelos ${ }^{3}$ \\ Paulo R. L. de Vasconcelos ${ }^{4}$ \\ Francisco D. Rocha ${ }^{4}$ \\ Ilana Zalcberg ${ }^{5}$ \\ Diego F. Coutinho ${ }^{5}$ \\ ${ }^{1}$ Department of Surgery, University Hospital Water Cantídio, Federal \\ University of Ceará, ${ }^{2}$ Research Laboratory in Haemoglobinopathies and \\ Genetics of Haematological Diseases, Federal University of Ceará, ${ }^{3} \mathrm{Hae}-$ \\ matology Service of Walter Cantídio University Hospital, ${ }^{4}$ Department \\ of Surgery, Federal University of Ceará, Fortaleza, and ${ }^{5}$ Cellular Ther- \\ apy Center of Porto Alegre, Center for Experimental Research, Porto \\ Alegre, Rio Grande do Sul, Brazil \\ E-mail: maritzacavalcante@hotmail.com
}

Keywords: myelodysplastic syndrome, TP53, myelofibrosis, prognosis

\section{References}

Bejar, R., Stevenson, K., Abdel-Wahab, O., Galili, N., Nilsson, B., Garcia-Manero, G., Kantarjian, H., Raza, A., Levine, R.L., Neuberg, D. \& Ebert, B.L. (2011) Clinical effect of point mutations in myelodysplastic syndromes. New England Journal of Medicine, 364, 2496-2506.

Della Porta, M.G. \& Malcovati, L. (2011) Myelodysplastic syndromes with bone marrow fibrosis. Haematologica, 96, 180-183.

Greenberg, P.L., Tuechler, H., Schanz, J., Sanz, G., Garcia-Manero, G., Solé, F., Bennett, J.M., Bowen, D., Fenaux, P., Dreyfus, F., Kantarjian, H., Kuendgen, A., Levis, A., Malcovati, L., Cazzola, M., Cermak, J., Fonatsch, C., Le Beau, M.M., Slovak, M.L., Krieger, O., Luebbert, M., Maciejewski, J., Magalhaes, S.M., Miyazaki, Y., Pfeilstöcker, M., Sekeres, M., Sperr, W.R., Stauder, R., Tauro, S., Valent, P., Vallespi, T., van de Loosdrecht, A.A., Germing, U. \& Haase, D. (2012) Revised international prognostic scoring system for myelodysplastic syndromes. Blood, 120, 2454-2465.
Kulasekararaj, A.G., Smith, A.E., Mian, S.A., Mohamedali, A.M., Krishnamurthy, P., Lea, N.C., Gäken, J., Pennaneach, C., Ireland, R., Czepulkowski, B., Pomplun, S., Marsh, J.C. \& Mufti, G.J. (2013) TP53 mutations in myelodysplastic syndrome are strongly correlated with aberrations of chromosome 5, and correlate with adverse prognosis. British Journal of Haematology, 160, 660-672.

Loghavi, S., Al-Ibraheemi, A., Zuo, Z., GarciaManero, G., Yabe, M., Wang, S.A., Kantarjian, H.M., Yin, C.C., Miranda, R.N., Luthra, R., Medeiros, L.J., Bueso-Ramos, C.E. \& Khoury, J.D. (2015) TP53 overexpression is an independent adverse prognostic factor in de novo myelodysplastic syndromes with fibrosis. British Journal of Haematology, 171, 91-99.

Mittelman, M., Oster, H.S., Hoffman, M. \& Neumann, D. (2010) The lower risk MDS patient at risk of rapid progression. Leukemia Research, 34, 1551-1555.

Ramos, F., Robledo, C., Izquierdo-García, F.M., Suárez-Vilela, D., Benito, R., Fuertes, M., Insunza, A., Barragán, E., Rey, M., Morales, J.M.G.,
Tormo, M., Salido, E., Zamora, L., Pedro, C., Sánchez-del-Real, J., Díez-Campelo, M., Cañizo, C., Sanz, G.F. \& Hernández-Rivas, J.M. (2016) Bone marrow fibrosis in myelodysplastic syndromes: a prospective evaluation including mutational analysis. Oncotarget, 7, 30492-30503. Saft, L., Karimi, M., Ghaderi, M., Matolcsy, A., Mufti, G.J., Kulasekararaj, A., Göhring, G., Giagounidis, A., Selleslag, D., Muus, P., Sanz, G., Mittelman, M., Bowen, D., Porwit, A., Fu, T., Backstrom, J., Fenaux, P., Macbeth, K.J. \& Hellström-Lindberg, E. (2014) p53 protein expression independently predicts outcome in patients with lower-risk myelodysplastic syndromes with del (5q). Haematologica, 99, 1041-1049.

Shah, A.A., Frierson, H.F. \& Cathro, H.P. (2012) Analysis of immunohistochemical stain used in different pathology practice settings. American Journal of Clinical Pathology, 138, 831-836.

Thiele, J., Kvasnicka, H.M., Facchetti, F., Franco, V., van der Walt, J. \& Orazi, A. (2005) European consensus on grading bone marrow fibrosis and assessment of cellularity. Haematologica, 90, 1128-1132. 